\title{
El texto del Primero sueño. Transmisión, editores, retos de la edición crítica
}

\section{The Text of the Primero Sueño. Transmission, Editors, Challenges for Its Gritical Edition}

\author{
Jorge Gutiérrez Reyna \\ Universidad Nacional Autónoma de México \\ Universidad del Claustro de Sor Fuana \\ jorge_gtz_reyna@hotmail.com
}

\section{Resumen}

El presente trabajo traza la historia textual del Primero sueño de sor Juana Inés de la Cruz. Da cuenta de su posible transmisión manuscrita, de su primera edición dentro del Segundo volumen de la obra de sor Juana, impreso en Sevilla en 1692, y de las varias ediciones antiguas españolas que, hasta 1725, reprodujeron el poema. Asimismo, se brinda información sobre editores del siglo XVII, como Juan de Orúe y Arbieto y José Llopis, quienes jugaron un papel fundamental en la transmisión del texto. Posteriormente, se hace un recuento de aquellos que, durante el siglo xx, han cuestionado el texto de los volúmenes antiguos, han tomado decisiones sobre éste y han ofrecido sus propias ediciones del Primero sueño: desde Ermilo Abreu Gómez en 1928, pasando por Alfonso Méndez Plancarte en 1951, hasta Alberto Pérez Amador en 2015. A partir de todo lo anterior, se busca establecer una serie de principios bajo los cuales debe procederse al momento de realizar una edición crítica del poema y se discuten, con base en ellos, algunos de sus loci critici.

\section{Palabras Clave}

Sor Juana Inés de la Cruz, poesía novohispana, edición crítica, crítica textual, transmisión textual.

\section{Abstract}

This article delineates the history of the text of sor Juana Inés de la Cruz's Primero Sueño. It gives an account of the possible manuscript transmission of the poem, of its first printed edition within the Segundo Volumen de las Obras de sor Juana, published in Seville in 1692, and of the various Spanish editions which, until 1725, reproduced the poem. This study also provides information about editors who played an important role in the textual transmission of the Primero Sueño during the $17^{\text {th }}$ century, such as Juan de Orúe y Arbieto and José Llopis. Furthermore, it addresses the topic of the 


\section{Jorge Gutiérrez Reyna}

editors who, during the $20^{\text {th }}$ century, questioned the accuracy of the old volumes' text, made editorial decisions about it, and offered their own editions of the text. These editors, and the publication dates of their editions, are as follows: Ermilo Abreu Gómez, 1928; Alfonso Méndez Plancarte, 1951, and Alberto Pérez Amador, 2015. Finally, this article indicates some basic principles that should be taken into consideration when creating a critical edition of the Primero Sueño, and discusses some of its loci critici.

\section{KEYwordS}

Sor Juana Inés de la Cruz, New Spain poetry, critical edition, textual criticism, textual transmission.

\section{RECEPCIÓN: 11/02/2019 \\ ACEPTACIón: 01/04/2019}

\section{"Entre vuestras plumas ando"}

$\mathrm{U}^{\mathrm{n}}$

n día de octubre de 1692, sor Juana Inés de la Cruz sostuvo entre las manos el Segundo volumen de sus obras reunidas, impreso en Sevilla por Tomás López de Haro pocos meses atrás. Para entonces, la poeta ya había publicado, gracias a las diligencias de María Luisa Manrique de Lara - virreina de la Nueva España entre 1680 y 1686 - , un primer volumen de obras reunidas, Inundación castálida (Madrid: Juan García Infanzón, 1689). Ese tomo había resultado ser un verdadero fenómeno editorial; circulaban ya tres reediciones impresas en Madrid, Barcelona y Zaragoza, publicadas bajo un título distinto (quizá menos pretencioso): Poemas de la única poetisa americana. A pesar, pues, de que había ya inundado con castálidas mareas al Viejo Mundo, y se sabía un éxito de ventas en aquel continente y en el propio, la llegada de este Segundo volumen debía resultar especial para sor Juana por varias razones. En medio de un México convulso — plaga de chahuiztle, un pueblo amotinado, edificios en llamas - , la autora habría paseado la vista por las primeras cien páginas y leería, seguramente emocionada, el alud de alabanzas que le propinaban los letrados de Europa, que, de manera bucólica, la llamaban Nise, pero también "Minerva Indiana", "Mexicano Fénix", "Americana Ninfa" - alguno, tensando la hipérbole, la nombra "única reina de la poesía"—. Respondería poco después a los elogios, con esa humildad suya, quizá enmascarada vanidad, con un poema bien conocido:

Y diversa de mí misma, entre vuestras plumas ando, no como soy, sino como quisisteis imaginarlo. $[\ldots]$ 


\author{
¿Qué mágicas infusiones \\ de los indios herbolarios \\ de mi patria, entre mis letras, \\ el hechizo derramaron? (2009: 51: vv. 17-20; 53-56). ${ }^{1}$
}

Los textos encomiásticos con que se engalanaba ese Segundo volumen parecen, a diferencia de los preliminares a los libros de la época, sinceros. Los lectores europeos, si bien habían quedado sorprendidos con las obras que conformaron la Inundación, se hallaban realmente entusiasmados con este nuevo tomo, que contenía las sutilezas teológicas de la Carta atenagórica, los "retóricos colores" de El divino Narciso, los enredos amatorios de Los empeños de una casa, y algunos sonetos, ahora célebres, como "Esta tarde, mi bien, cuando te hablaba" o "Detente, sombra de mi bien esquivo". Entre todas estas piezas incluidas en el Segundo volumen, el Primero sueño ocupa, sin duda, un sitio prominente.

\title{
"Porque voraz el tiempo no las borre": del manuscrito a la imprenta
}

En este Segundo volumen, la monja daba a la imprenta por primera vez su obra más ambiciosa, una silva en cuya composición se habían conjuntado, se cifraban, sus dos más altas aspiraciones vitales: la búsqueda del conocimiento y la pasión por hacer versos. El argumento del poema no es en modo alguno enrevesado, y se lo comunicó la propia sor Juana a Diego Calleja, quien publicó las palabras de la monja en su conocida Aprobación a la Fama y obras póstumas: "Siendo de noche, me dormí; soñé que de una vez quería comprehender todas las cosas de que el universo se compone; no pude, ni aun divisas por sus categóricas, ni a un solo un individuo. Desengañada, amaneció y desperté" (2010b: 29). Esa línea argumental, que la autora hace parecer tan simple, no es recta: a lo largo de los 975 versos que lo componen, el poema se extiende en las descripciones de la caída de la noche ("Piramidal, funesta...") o del triunfo de la aurora ("Amazona de luces mil vestida"); se introduce hasta la oscura cueva donde el "rey" de los animales, el león, duerme, como se creía en la época, con los ojos abiertos — "aun con abiertos ojos no velaba" - y, en un parpadeo, asciende y planea a la par del vuelo altísimo del águila, "que puntas hace al cielo" y se "bebe los rayos" del sol.

\footnotetext{
${ }^{1}$ Cito a sor Juana por la edición de sus Obras completas. Cuando la cita proviene del primer tomo, de la Lírica personal, empleo siempre la que realizó Antonio Alatorre; para el segundo y tercer tomo, uso la de Alfonso Méndez Plancarte, y para el cuarto, la de Alberto G. Salceda. Consigno el número que ocupa la obra citada en dichos volúmenes, seguido del número de versos o de líneas, según corresponda.
} 


\section{Jorge Gutiérrez Reyna}

Si bien, en esencia, las diferencias son muchas más que las similitudes, el mecanismo compositivo, la forma métrica de la silva y el aspecto más superficial del lenguaje poético del Sueño imitan deliberadamente las Soledades, Primera y Segunda, de Luis de Góngora, escritas durante el primer cuarto del siglo XVII. El epígrafe que antecede al poema en la edición de 1692 es contundente a este respecto: “que así intituló y compuso la madre Juana Inés de la Cruz, imitando a Góngora". No faltó quien se apresurara a conceder la victoria en esta competencia a la monja mexicana, que se atrevía a batirse con el mayor poeta de España y su obra maestra. Ello consta en los preliminares del Segundo volumen: este poema, afirma el carmelita Gaspar Franco de Ulloa, "imita, o por mejor decir, excede al celebérrimo Góngora" (2010a: 36); Juan Bautista Sandi de Uribe dice que a sor Juana, por su Sueño, "sus Soledades Góngora le ofrece" como un tributo (2010a: 77). Pedro del Campo asienta, al fin, que "cuantos soñaron" en las cumbres del Parnaso, ahora que aparece el Sueño de Juana Inés, "quisieran no haber soñado" (2010a: 81).

Aunque se publicó por primera vez en 1692, es muy difícil, cuando no imposible, fechar con precisión la escritura del Sueño. Se sabe, sin embargo, que, como la mayor parte de la poesía de su tiempo, circuló, antes de su impresión, de forma manuscrita. La misma poeta asegura, en unas líneas archiconocidas de la Respuesta a sor Filotea, que el Sueño ya estaba escrito en marzo de 1691, fecha en la que se firma dicha Respuesta; se puede aseverar que también circulaba entre los lectores, pues sor Juana dice que otros le "llaman" Sueño a su composición: "no me acuerdo haber escrito por mi gusto sino es un papelillo que llaman El Sueño" (1957: 405: líneas 1266-1267). Al testimonio de la propia autora, hay que añadir el del anónimo "caballero recién venido a la Nueva España", que publica en el Segundo volumen un romance dedicado a la monja y, por tanto, escrito antes de 1692:

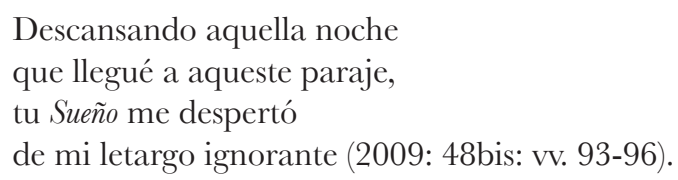

Así pues, puede afirmarse, con base en la información con la que contamos, que el poema ya andaba de mano en mano al menos un año antes de su publicación. ¿Lo escribiría sor Juana por esas fechas? Imposible determinarlo. Aunque es de suponer que una obra de esta envergadura le tomara a su autora muchos años de trabajo: bien pudo emprender su composición varios años antes de 1691 y quizá, como se sabe que ocurrió con las Soledades, circularían manuscritas diversas versiones del poema, previas a la final, que está preservada en el Segundo volumen. ${ }^{2}$ Se ignora el paradero, si es que

${ }^{2}$ La transmisión de la obra manuscrita de sor Juana, en los años previos a la publicación de sus obras reunidas en España, es todavía un terreno inexplorado. De este periodo se cono- 
han sobrevivido a la voracidad de los siglos, de esos papeles. Si no hubiera llegado a las prensas en 1692, quizá hoy desconoceríamos las palabras del Sueño; por fortuna, éstas quedaron plasmadas sobre la página en blanco, para que así - como dice un verso del poema - "voraz el tiempo no las borre".

Gracias a los testimonios anteriores, dicho sea de paso, se sabe también que, previo a su publicación, el poema se llamaba el Sueño, a secas. Lo más probable es que sor Juana decidiera, ya sea por iniciativa propia o por consejo de terceros, intitularlo, poco antes de sacarlo a la luz en 1692, Primero sueño, no porque pensara escribir un Segundo, sino para equipararlo con la Primera Soledad. Ello constituye una estrategia editorial de ventas (Sabat, 1995: nota 21), pero también, y sobre todo, una toma de postura contundente: la monja mexicana anuncia a sus lectores del otro lado del Atlántico que ha escrito algo capaz de compararse con la obra mayor del mismísimo don Luis de Góngora.

Hasta no encontrar algún manuscrito, en lo que respecta al texto de Primero sueño, no nos queda sino refugiarnos, como primer y más antiguo testimonio, bajo la sombra del Segundo volumen. Afortunadamente, esa sombra está lejos de ser funesta: de los antiguos tres tomos de obras reunidas es éste el que ofrece mejores y más cuidados textos. Los de Inundación castálida, como afirma la propia autora en un romance que sirvió de "Prólogo al lector", no pudieron corregirse por "la prisa de los traslados" (1: v. 36); los de Fama y obras póstumas (Madrid: Manuel Ruiz de Murga, 1700), como se adivina por el título, no pudo ni revisarlos ni corregirlos nuestra poeta. A la reedición del primer tomo, Poemas (Madrid: Juan García Infanzón, 1690), sor Juana añadió algunos textos que no aparecían en la Inundación, pero no enmendó los que ya se habían publicado (véase Gutiérrez: XV-XVIII). Los del Segundo volumen, en cambio, sí fueron revisados y corregidos por la monja jerónima; ello consta gracias a las significativas diferencias que existen entre las lecciones que ofrece este tomo de obras reunidas y las que presentan las sueltas mexicanas de la Carta atenagórica - llamada luego Crisis sobre un sermón (Eguía: 285-295)-, de villancicos y de El divino Narciso, publicadas en América con anterioridad (Gutiérrez: XVIII-XxIV; Galicia y Gutiérrez). Si había una versión previa del Sueño, ésta seguramente se corrigió, como se hizo con otros textos, antes de ser enviada para su publicación en el Segundo volumen.

ce únicamente el, así llamado por Antonio Alatorre, Ms. Moñino, resguardado en el Fondo Antonio Rodríguez Moñino de la Biblioteca de la Real Academia Española (Mss. M-RAE RM2155[2]); se trata de unos cuantos folios en los que algún admirador copió, antes de que llegaran a las prensas, varios poemas de la Décima Musa. Fue descrito por primera vez por Bryant (277-285) y Alatorre (2009: 777-782). 


\section{Los editores que soñaron con sor Juana}

Sor Juana preparó la segunda entrega de sus obras con tiempo y dedicación: debió pasar gran parte del año de 1690 reuniendo y revisando los materiales que remitiría a España, a más tardar a principios de 1691 (Eguía: 271). Esos "papelillos" — como los llama ella misma en la dedicatoria del volumen - iban encaminados a don Juan de Orúe y Arbieto. A este caballero, oriundo de Vizcaya, la jerónima dedica su Segundo volumen. Se sabe que fue miembro de la Orden de Santiago desde 1689, que sirvió en la marina de Andalucía y que hizo fortuna como comerciante en Sevilla, ciudad en la que residió en 1692. Tuvo estrechos lazos comerciales con la Nueva España, donde estuvo presente varias veces. ${ }^{3}$

Por una suerte de inercia, la crítica ha asegurado que el Segundo volumen, al igual que la Inundación, se realizó gracias al mecenazgo de María Luisa, condesa de Paredes. Octavio Paz considera que "el caballero vizcaíno era un testaferro de la condesa de Paredes" (559); Glantz escribe que los elogios que anteceden al tomo se reunieron "a instancias de la condesa de Paredes" (XI); Eguía, por su parte, apunta que "aunque [la virreina] está también detrás de este tomo segundo, lo que hace es abandonar su papel protagónico en la edición (no estaría de más averiguar por qué)" (264). Creo que, más bien, deberíamos dejar de pensar que María Luisa estuvo "detrás" del Segundo volumen.

Si se revisan los preliminares, se notará enseguida que la condesa brilla por su ausencia; Orúe y Arbieto, en cambio, acapara los reflectores. A este hombre, ya lo dije, sor Juana dedica todo el libro, y es, precisamente, en la dedicatoria donde afirma que fue el caballero vasco quien le solicitó los textos: ella no hace sino "obedecer a Vm. en su entrega". En una "Nota", se lee que Orúe y Arbieto, antes de dar a la imprenta las obras del Segundo volumen, "o por anticiparles el gusto de leerlas, o por examinar si corrían uniformes en el aplauso universal con que fue recibido el primer tomo, las consultó con algunos varones insignes en religión y letras, remitiéndoselas para que las viesen". Al constatar que los elogios de estos "varones insignes" confirmaban "eruditamente [...] la fama de la autora", "los ofrece consecutivos, ocupando las veces del más proporcionado y elegante preludio" al volumen (2010a: 16). Es también al comerciante de Vizcaya a quien el rey concede licencia y privilegio: "Por cuanto por parte de vos, don Juan de Orúe, caballero de la Orden de Santiago, vecino de la ciudad de Sevilla, se nos hizo relación, deseábades dar a la imprenta un libro intitulado..." (2010a: 96).

Hay que recordar, asimismo, que el Segundo volumen se imprime en Sevilla, y que casi todos los elogiadores desempeñan cargos en dicha ciudad o en alguna otra de

\footnotetext{
${ }^{3}$ Hay documentos en el Archivo General de Indias que prueban la presencia de este personaje en México (véase Galicia y Gutiérrez: 222-223). Infundada del todo es la aseveración de Octavio Paz: "Juan de Orúe y Arbieto no estuvo nunca en México ni conoció a sor Juana" (559).
} 
Andalucía (Cádiz, por ejemplo). María Luisa, por esas fechas, estaba en Madrid, ocupada en otros asuntos: en abril del 92 falleció su esposo, y ese mismo mes ella recibió de la Corona "los honores de Grande de España para sí y sus sucesores" (Calvo y Colombi: 91). Insisto: todo parece indicar que María Luisa tuvo muy poca o nula injerencia en la preparación y edición del Segundo volumen. Habría que preguntarse por el tipo de relación de sor Juana con Orúe y Arbieto - ¿ise conocieron personalmente en alguno de los viajes de este último a México?- y con el selecto grupo de intelectuales andaluces - casi todos jesuitas, por cierto - que la elogian.

$\mathrm{Al}$ igual que la Inundación, el Segundo volumen se reeditó varias veces; en todas ellas se incluyó, por supuesto, el Primero sueño. El admirador número uno de sor Juana vivía en Barcelona, se llamaba José Llopis, y daba la casualidad de que era impresor, amén de un hábil comerciante. Antes de hablar de la relación de Llopis con el texto del Primero sueño, quizá convenga precisar algunos aspectos sobre este personaje. Sor Juana publica en Puebla por primera vez en 1689, el mismo año que en Madrid se imprimía la Inundación castálida, tres juegos de villancicos salidos de la imprenta de Diego Fernández de León; con este poblano - cuya marca de impresor era, por cierto, muy parecida a la del español - alguna relación comercial debía tener Llopis, pues, poco después de impresos, le llegan esos villancicos a Barcelona, junto con la suelta mexicana de El divino Narciso. Fue entonces cuando debió ocurrírsele la idea de reeditar el primer tomo de sor Juana, que se vendía como pan caliente, pero con esos textos recién llegados de la Nueva España, hasta ese momento desconocidos en aquel lado del Atlántico. Así, en 1691, publicó, "a su costa", es decir, con dinero de su propio bolsillo, una reedición del primer tomo de su admirada sor Juana con añadidos nunca antes vistos en el Viejo Continente: Poemas de la única poetisa americana, musa décima.

El libro debió venderse muy bien, porque poco después Llopis se mudó a un taller más grande y se convirtió en el impresor más prestigioso de Barcelona (Rodríguez: 2728). Mientras Llopis hacía su reedición de la Inundación castálida, sor Juana preparaba, simultáneamente, el Segundo volumen, en el que se añadieron los textos que el barcelonés ya había dado a conocer, pero con correcciones de la autora: es decir, Llopis tuvo la primicia, pero las versiones definitivas, autorizadas, no llegaron a los lectores sino hasta la publicación del Segundo volumen. Este hecho, aunado a que la edición carece de algunos documentos legales de rigor - lo que ha hecho pensar que se trató de una edición "pirata" (Eguía: 93)-, me orilla a concluir que los volúmenes de Llopis están desvinculados del que se podría llamar el proyecto editorial oficial de sor Juana, al que ella misma provee con textos revisados (véase Gutiérrez: XIX-XXIv; Galicia y Gutiérrez). ${ }^{4}$

\footnotetext{
${ }^{4}$ La edición de Llopis sí estaba desvinculada del proyecto oficial, pero, por supuesto, no era "pirata" o falsificada: "no deben confundirse estas ediciones ilegales con otras, perfectamente lícitas, llevadas a cabo en otros reinos que el de Castilla, que estaban sujetos a otra normati-
} 


\section{Jorge Gutiérrez Reyna}

En cuanto apareció en Sevilla el Segundo volumen, Llopis, como el astuto lobo que era, decidió repetir el éxito obtenido con Poemas. Y no sólo lo repitió, sino que se superó a sí mismo: en 1693, hasta donde se sabe, el barcelonés publicó tres reediciones de la segunda entrega de obras reunidas de sor Juana (Sabat, 1974), y volvió a emplear la estrategia mercantil que había usado en la impresión del primer tomo: añadió los villancicos a santa Catarina, salidos del taller poblano de Diego Fernández de León en 1691, hasta entonces desconocidos en la Península (Gutiérrez: XXII-XXIV). Aunque en su portada, engañosamente, se lee que han sido aumentados "por su autora", también dichos volúmenes debieron estar desvinculados del proyecto oficial, y en ellos sor Juana no tuvo injerencia alguna. Si bien los tres llevan el título de Segundo tomo de las obras de soror fuana Inés de la Cruz, pueden diferenciarse fácilmente, sobre todo, por los grabados que adornan sus portadas. El primero que se realizó (al que asigno la sigla B1) ostenta un grabado con motivos vegetales; el segundo (B2), uno que representa un tazón con frutos y pájaros; el tercero (B3), un tazón similar, pero del que los pájaros han ya volado. La versión "pirata", pues, se vendió mucho mejor que la oficial, que sólo se imprimió una vez.

En estas impresiones de José Llopis iba incluido, por supuesto, el Primero sueño. El texto que ofrece el barcelonés deriva, sin lugar a dudas, del Segundo volumen $(S)$. No obstante, las prisas por satisfacer a un público lector sediento de la obra de la monja mexicana, que lo orillaron a imprimir tres libros de tal envergadura en un año, entre otras cosas, hacen que el texto que Llopis imprime del Sueño sea, sobre todo en B3, deplorable. Considérense sólo los siguientes versos, impresos de manera correcta en $S$, $B 1$ y $B 2$, pero tristemente deturpados en la tercera reedición del impresor barcelonés:

911 contra la que, tirana usurpadora $S B 1 B 2$

917 Pero apenas la bella precursora $S B 1 B 2$

921 si bélicos clarines de las aves $S B 1 B 2$

926 embarazada, bien que hacer alarde $S B 1 B 2$ 970 de orden distributivo, repartiendo $S B 1 B 2$ contra la que, tirana usurpedora $B 3$ Pero apenas la bella percusora $B 3$ si belicosos clarines de las aves $B 3$ embarazada, bien que hacer alerde $B 3$ de orden distributivo, repitiendo $B 3$

Debo precisar que cuando hago a Llopis el responsable de los errores en las varias ediciones de la obra de la monja mexicana que salieron de su imprenta estoy, por supuesto, realizando una especie de abstracción. El impresor, es decir, la cabeza del taller tipográfico fungía con frecuencia, en el siglo XVII, como un editor, en el sentido actual del término. Sin embargo, hay varios actores involucrados en el proceso de producción de un libro en la época. El más importante de esos actores era el

va. Por ejemplo, las obras más importantes impresas en Madrid aparecen el mismo año o al siguiente impresas en Barcelona legalmente" (Blecua: 177-178). 
componedor o cajista, que tenía en sus manos el original del texto a imprimir e iba formando, con los tipos móviles, cada uno de los folios (Blecua: 172). Así pues, si digo que Llopis, o cualquier otro de los editores antiguos de sor Juana, cometió un error, no me refiero forzosamente al editor-impresor en sí, sino a cualquiera de los actores de su taller involucrados (en especial, el cajista) en el proceso de elaboración del impreso en cuestión.

Casi veinte años después de la muerte de sor Juana en 1695, el Sueño volvió a imprimirse en un volumen madrileño que se llamó Obras poéticas de la musa mexicana (1714), el cual corrió a cargo de José Rodríguez de Escobar, quien, según reza la portada, era impresor de la "Santa Cruzada y de la Real Academia Española". Esta última se había fundado apenas un par de años antes: ¿fue ese volumen uno de los primeros encargos que hizo la Academia a su impresor? Más de diez años después, en 1725, se imprimieron en el taller de Ángel Pascual Rubio, por primera vez, los tres tomos simultáneamente: se trata del primer intento en la historia de realizar unas Obras completas de sor Juana. En el segundo de estos tomos se incluye el Primero sueño. No obstante, estas dos reediciones de 1714 y 1725 ( $O$ y $A$, respectivamente) son poco significativas: su texto deriva de las ediciones de Llopis, en específico de $B 1$, que, como ya se vio, dista de ser excelsa.

Los pocos ejemplos de variantes entre los distintos testimonios del poema que ofrezco a continuación contribuyen a establecer un stemma para las ediciones antiguas. He dicho ya que el texto de las ediciones de Llopis deriva directamente del Segundo volumen $(S)$; ahora bien, ¿ ¿tra edición deriva también de este último? Como se observa en el v. 135, es posible afirmar que no: cuando B1, B2 o $B 3$ ofrecen una lección, todas las ediciones subsecuentes la copian. Como se aprecia en los vv. 17 y 27, $O(1714)$ y $A$ (1725) copian precisamente a $B 1$; lo copian, además, por separado, es decir, $A$ no deviene de $O$, como queda claro en el v. 56 . Por último, es posible asegurar que $B 3$ deviene de $B 2$, pues ésta introduce errores que no estaban en aquélla, como en el v. 360:

17 empañaba $S B 2 B 3$

27 Nictimene $S B 1 O A$

56 no $S B 1 B 2 B 3 A$

135 guarda cálculo $S$

360 mirar $S B 1 B 2 O A$ empeñaba $B 1 O A$

Victimene $B 2 B 3$

om $O$

guarda el cálculo B1 B2 B3 OA

mudar B3

Dicho lo cual, el stemma quedaría como sigue: 


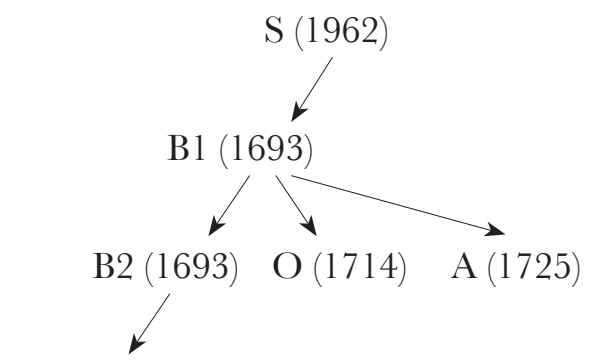

B3 (1693)

Los tiempos, las sensibilidades, cambian. Luego de ser un best seller, durante buena parte del siglo XVIII y todo el XIX, llegaron a las prensas únicamente fragmentos del Sueño que, por lo general, iban acompañados de algún despectivo comentario. En 1869, por poner un ejemplo, Francisco Pimentel publica en México Biografia y crítica de los principales poetas mexicanos. Tras reproducir los primeros 18 versos de la silva de sor Juana, concluye: “¿Qué se saca en limpio de todo esto? Nada absolutamente, y lo mismo fuera si nos propusiéramos aburrir al lector insertando la composición entera" (citado en Alatorre, 2007: 148).

Tendríamos que esperar más de doscientos años para que el Sueño de sor Juana volviera a imprimirse en letras de molde. No suele darse a Ermilo Abreu Gómez el lugar que merece entre los sorjuanistas del siglo xx. Habría que recordar que a este polígrafo yucateco le debemos, entre otras cosas, la primera edición moderna íntegra del poema, aparecida en 1928 en la revista Contemporáneos $(A G)$. Esta edición fue semi-crítica, anotada, y constituye un testimonio interesante y sui generis: nunca más veríamos el Primero sueño entre reproducciones de los lienzos surrealistas de Giorgio de Chirico, reseñas de Xavier Villaurrutia y anuncios de un talco llamado La Rosa de Guadalupe. En su edición, Abreu Gómez reproduce, salvo raras excepciones, las lecciones del Segundo volumen, aunque también tuvo a la mano B3, $O$ y $A$. El texto del yucateco es, en términos generales, bastante correcto; si no fuera por la desastrosa puntuación y la desafortunada - casi siempre inexplicable - separación de la silva en estrofas, me atrevería a afirmar que ésta es una de las mejores ediciones que se hicieron del poema en el siglo xx. Sea como fuere, hay que decirlo sin rodeos: Abreu Gómez le restituyó la obra maestra de la Décima Musa a la literatura mexicana y no merece permanecer en la sombra a la que se le ha relegado por casi un siglo.

Tras sus huellas fue Karl Vossler, quien en 1941 publicó, en Berlín, el Sueño de sor Juana en español y alemán bajo el título de Die Welt im Traum (El mundo en el sueño) (KV). El texto ofrecido por el estudioso alemán perpetúa numerosas erratas de las ediciones de José Llopis, pero también sugiere correcciones interesantes, como se verá más adelante. La mayoría de ellas las retomaría Alfonso Méndez Plancarte, que publicó 
el poema en 1951, dentro del primer tomo, intitulado Lírica personal, de las ya clásicas Obras completas $(M P)$. Vinieron luego las ediciones de la silva de Gerardo Moldenhauer, impresa en Buenos Aires en el 53 (GM); de Alberto Pérez Amador, que vio la luz en 1996 y reapareció corregida y aumentada en 2015; de Georgina Sabat de Rivers y Elías Rivers en 2004 (dentro de la antología Poesía, teatro, pensamiento: lírica personal, lírica coral, teatro, prosa) (SR); y, finalmente, de Antonio Alatorre, que en 2009 dio a las prensas lo que él mismo llamó "otra edición” de la Lírica personal $(A A)$.

Ha habido, por supuesto, otras muchas ediciones modernas del Sueño, pero éstas se limitan a reproducir el texto de alguna de las que aparecen en la lista del párrafo anterior. En esa lista, pues, sólo sumo aquellas ediciones cuyos responsables han cuidado, cuestionado y tomado decisiones sobre el texto que presentan. Ninguna de las arriba mencionadas, salvo la de Pérez Amador, es una edición propiamente crítica. En ningún caso los editores tuvieron a la mano todos los testimonios que los antecedieron: Vossler, por ejemplo, compulsó $S, B 3, O$ y $A$; Méndez Plancarte revisó estas mismas y la edición de Abreu, pero no la de 1928 - que sabía digna-, sino la terrible de 1940 (México: Botas), que aprovechó para pulverizar a su antecesor. Ahora bien, en ningún caso los editores realizaron una compulsa sistemática de los testimonios: registran las variantes que, desde su punto de vista, resultan más interesantes. Por esta misma razón, ninguna edición del Sueño ofrece, propiamente, un aparato de variantes. ${ }^{5}$

\section{Los caracteres del estrago: unos cuantos casos problemáticos}

Hace algunos años, la Academia Mexicana de la Lengua me encomendó la edición crítica de una antología que lleva por título, tentativamente, Primero sueño y otros poemas, la cual formará parte de la colección Clásicos de la Lengua Española. En lo referente a la edición del Sueño, luego de compulsar cada una de las ediciones antiguas y modernas, cuyos rasgos expuse en términos generales líneas arriba, y de elaborar el respectivo aparato de variantes, llegué a tres conclusiones a las que, debido a que no

\footnotetext{
${ }^{5}$ Pérez Amador tiene el mérito de haber sido el primero en realizar una edición crítica del Primero sueño. Ahora bien, me permito señalar algunos aspectos que la demeritan. Aun cuando presenta un aparato de variantes, éste es francamente inmanejable: ofrece a la par dos textos, uno con ortografía modernizada y otro con las grafías de la edición de 1692, y para cada uno genera una aparato crítico distinto; consigna las variantes de puntuación — nos informa si hay comas, si se suprimen, si se sustituyen por punto y coma, etcétera-, pero sin proponerse comprender el sistema detrás de la misma, si es que lo hay, en las ediciones antiguas; como he podido comprobar, no siempre se cotejan con cuidado los testimonios, pues hay numerosas variantes que no registra. Además, aunque considera todos los testimonios antiguos, no los filia ni jerarquiza; su compulsa de las ediciones modernas no contempla ni la de Abreu Gómez, ni la de Vossler, ni la de los Rivers.
} 
contaban con la información suficiente, no llegaron los editores anteriores de la silva de sor Juana. En primer lugar, puedo presumir que el único testimonio procedente de un texto revisado por la misma sor Juana es el Segundo volumen. El texto publicado en este tomo constituye, hasta donde se sabe, la última voluntad de la autora; ya mostré que las tres ediciones barcelonesas de 1693 no fueron ni revisadas ni corregidas por la jerónima. Por ende, puedo aseverar, en segundo lugar, que toda modificación realizada al texto del Segundo volumen debe atribuirse, forzosamente, a los editores de los testimonios subsecuentes. Tercera y última conclusión: si bien todos los cambios introducidos al Segundo volumen se deben a los editores, entre éstos hay que jerarquizar: un cambio introducido por alguien tan descuidado como José Llopis no puede considerarse, obviamente y por muchos motivos, al mismo nivel que otro introducido por la sagacidad de Méndez Plancarte o Antonio Alatorre, quienes suelen ser cautelosos y acostumbran tener razones de peso al proponer alteraciones al texto del poema.

Por tanto, al realizar una edición crítica del Primero sueño, hay que proceder bajo la máxima siguiente: la editio princeps tiene la razón hasta que se demuestre lo contrario. Ha prevalecido entre los editores del poema, ya desde el siglo XVII, una extraña manía por enmendarle la plana a sor Juana; a veces, en especial ciertos editores modernos, parecen más preocupados por ofrecer lecciones novedosas, distintas a las de su antecesor, que por cuidar aquello que sor Juana efectivamente escribió. Así pues, una edición crítica del Sueño tendría que ceñirse, en principio, al texto del Segundo volumen. La experiencia nos ha enseñado que, cuando no se procede de este modo, pueden cometerse errores graves al momento de editar el poema.

Es bien conocido el caso del verso 94, en el que nada una criatura llamada $\mathrm{C}^{A l-}$ mone o Alcione? El pasaje (vv. 86-96) nos sumerge en las profundidades del mar, en cuyos lechos lamosos, los siempre mudos peces, dormidos, son mudos dos veces; entre estos seres escamados, se cuenta una tal Almone (es lo que se lee en todos los testimonios antiguos), quien, según se dice, en otro tiempo había sido engañosa encantadora ('hechicera') y había transformado a sus simples ('ingenuos') amantes en peces, animal en el que ahora ella también se halla transformada:

El mar, no ya alterado,
ni aun la instable mecía
cerúlea cuna donde el sol dormía,
y los dormidos, siempre mudos peces,
en los lechos lamosos
de sus obscuros senos cavernosos,
mudos eran dos veces;
y entre ellos la engañosa encantadora
Almone, a los que antes
en peces transformó, simples amantes,
transformada también vengaba ahora.

82 (an)ecdótica * vol. III, núm. 2, julio-diciembre 2019 
Cuando Karl Vossler realizó su edición del Sueño en 1941, no pudo encontrar información sobre Almone, que aparece, como ya dije, en todas las ediciones antiguas, y supuso que debía tratarse de un error; propuso, a falta de algo mejor, sustituir el nombre por Alcione. Sin embargo, la bella historia de Alcione, esposa del rey tracio Céix, que se narra en las Metamorfosis (XI: vv. 410 y ss.), nada tiene que ver con lo que refiere sor Juana en su poema. La reina era una esposa fidelísima que, al enterarse de que su marido se embarcaría hacia el templo de Claros, temió perderlo para siempre entre las tormentas del océano; le ruega que realice el viaje por tierra o, en todo caso, la lleve consigo para que ambos corran la misma suerte, cualquiera que ésta fuese. No logra convencerlo, y el rey emprende el trayecto en una barca, no sin antes prometer su regreso. Los temores de Alcione no resultaron infundados y Céix muere durante una brava tempestad en altamar. Por intercesión de Juno y en sueños, la reina se entera del terrible suceso y, enloquecida, sale a la playa desde la que había zarpado su marido. El cuerpo de Céix (que al fin cumple su promesa) llega entonces hasta Alcione arrastrado por las olas. Ambos, de pronto, se transforman en alciones (ave que también se conoce como martín pescador), y juntos se van volando por el cielo.

Méndez Plancarte aceptó la corrección de Vossler con entusiasmo y ofreció a nota una justificación nada convincente: Alcione "metafóricamente" transformaba a sus enamorados en peces, "cautivándolos en las redes de su amor". Cabe decir que de esos supuestos amantes de la reina no se habla nunca en las Metamorfosis. No fue sino hasta 1965 cuando comienza a aclararse esta cuestión, gracias a que Corripio Rivera señaló la importancia de una muy libre traducción que Jorge de Bustamante hizo de Ovidio en la primera mitad del siglo XVI, muchas veces reimpresa en las décadas siguientes. En esa traducción, aparece una hechicera, sin nombre en el Ovidio en latín, que es bautizada como Almone; ésta sí transformaba a sus amantes en peces, y luego, en venganza, ella también había sido convertida en lo mismo:

O por ventura queréis que os traiga a la memoria otra [conseja] de Almone, la cual estaba en un cosario puerto a la costa de la mar burlando y engañando a cuantos por allí pasaban, a los cuales, después de gozado sus personas y con astucias y mañas robándoles sus haciendas (como hoy día otras muchas hacen) con sus encantamientos y yerbas, los convertía en peces; aunque de esto llevó su pago, que uno vino allí a donde ella estaba, el cual, pareciéndole muy bien, le tomó por amigo y éste después supo tanto del arte que supo robar él solo lo que ella había robado a muchos, y la volvió también en pez como ella había hecho a otros (1664: f. 71 r). ${ }^{6}$

${ }^{6}$ Si se consulta a Ovidio directamente, podrá constatarse lo mucho que Bustamante añadió a la historia en su traducción. En el original sólo se lee: "Nais an ut cantu nimiumque potentibus herbis / verterit in tacitos iuuenalia corpora pisces, / donec idem passa est". Los estudiosos actuales traducen Nais - el nombre del personaje a quien Bustamante llamó Almone- como náyade; por ejemplo, Rubén Bonifaz Nuño: "o cómo, con canto y hierbas de sobra potentes, la náyade/ volviera 


\section{JJorge Gutiérrez Reyna}

Creo que no hay necesidad de explicar nada "metafóricamente" ni de darle más vueltas al asunto: con base en la información que se posee, resulta evidente que sor Juana tomó el nombre de Almone de la traducción de Bustamante y que esta lección que aparece en todos los testimonios antiguos, la cual anduvo muchos años alterada en la edición de Méndez Plancarte, es la que debe imprimirse. Justamente, eso había hecho ya Abreu Gómez; vinieron a resarcir, al fin, el error los Rivers, Pérez Amador y Alatorre.

Tres son los órganos que, mientras el resto duerme, resisten al sueño y se mantienen insomnes, absortos en sus labores: el corazón, los pulmones y el estómago. Sobre este último escribe sor Juana:

Y aquella del calor más competente
centrifica oficina,
próvida de los miembros despensera,
que avara nunca y siempre diligente
ni a la parte prefiere más vecina
ni olvida a la remota,
y en ajustado natural cuadrante
las cuantidades nota
que a cada cual tocarle considera
del que alambicó quilo el incesante
calor en el manjar... (vv. 234-244).

La lección centrifica se encuentra en $S, B 1, O$ y $A$, que dependen de $B 1 ; B 2$ introduce la variante cientifica, que aceptan, entre otros editores modernos, Vossler, Méndez Plancarte, los Rivers y Pérez Amador. La lección centrifica es, sin duda, la correcta, y hacen bien en imprimirla Abreu Gómez y Alatorre: no se trata de una errata corregida por la edición de Llopis, la cual, como ya señalé, no introduce nunca correcciones de la autora y, además, deturpa en numerosas ocasiones el texto. El hecho de que el adjetivo centrifico no aparezca en ningún diccionario o en otros autores de la época no es razón suficiente para descartarlo como la palabra que la jerónima tenía en mente al momento de escribir su poema. En primer lugar, la forma del adjetivo es transparente y no resulta difícil, para ningún lector, atisbar a través de ella su significado: 'relativo al centro', 'central'; ello encaja perfectamente con lo que dice nuestra poeta del estómago: oficina que distribuye desde el centro del cuerpo los nutrientes que cada parte del organismo necesita, sin importar que ésta se encuentre vecina o remota. En segundo

juveniles cuerpos en tácitos peces,/ hasta que sufrió mismo..." (1979, IV: vv. 49-51). Una traducción española, realizada por Sánchez de Viana en el siglo XVI, sí reserva a la náyade el nombre de Nais: "O cómo en mudos peces convertido/ ha Nais los mancebos con su canto,/ hasta que quien sí lo mesmo ha padecido" (1589: fol. 33r). 
lugar, nos consta que sor Juana era creativa con su léxico, le gustaba emplear palabras infrecuentes que no registrarían los diccionarios sino hasta muchos años después o que jamás lo harían. Véase, por ejemplo, en el mismo Sueño, el caso de conticinio (v. 151), que el DRAE no consigna sino hasta 1780; o el de fluxible, adjetivo que aparece en el DRAE por primera vez en 1803, pero que utiliza la poeta en diferentes lugares de su obra, como en el Neptuno alegórico: "...émulo de Apeles/ con docta imitación de sus pinceles/ al mar usurpa la fluxible plata” (1957: 402: vv. 71-73); finalmente, en sus ovillejos, tilda a una nariz de tortizosa, término que ella inventa para referir a algo 'desmesurado o desproporcionado': "que hay nariz tortizosa, tan tremenda,/ que no hay geómetra alguno que la entienda” (2009: 214: vv. 265-266).

$\mathrm{Al}$ caer la noche, las aves nocturnas de Primero sueño - la lechuza, los murciélagos, los búhos - orquestan una lúgubre sinfonía:

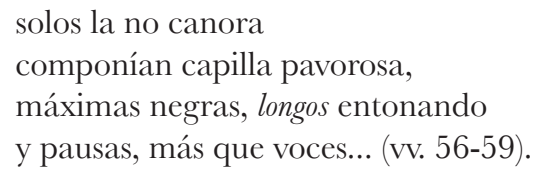

En todos los testimonios antiguos - y en Abreu Gómez - se lee longos. Vossler creyó que se trataba de una errata y enmendó: longas. Todos los editores modernos aceptan la enmienda; pero insisto: hay que ceñirse al Segundo volumen. El longo es una nota musical bien conocida en la época. El diccionario de Terreros y Pando (1780) consigna el término: "en la música, es una nota blanca figurada por un cuadrado y una colita, y vale la mitad de una máxima o cuatro medidas". Aparece también varias veces en una tratado musical que, nos consta, sor Juana poseía y leía con aguda atención: El Melopeo y el maestro de Pedro Cerone (véase Gutiérrez: nota 12). Ahí, el longo se cuenta entre los nueve diferentes "puntos o notas, llamadas comúnmente figuras, usadas en canto llano" (Cerone: 412). En suma: la corrección de Vossler, acatada, salvo por Abreu Gómez, por todos los editores subsecuentes, sale sobrando; la lección de longos, impresa en $S$ y en todas las ediciones antiguas, es correcta y no hace falta enmendar nada.

Como he mencionado ya, el Segundo volumen constituye un testimonio confiable del texto de Primero sueño: sor Juana debió enviar a Sevilla un manuscrito, si no perfecto, bastante limpio de su obra maestra. Empero, eso no quiere decir que en el trajín de la imprenta no se hayan cometido errores. Para resarcirlos, no queda más que recurrir a las enmiendas de los editores, antiguos y modernos, escuchar sus razones y decidir si sus propuestas, en cada caso, son o no pertinentes. Estoy convencido de que en muy contadas ocasiones los editores (incluso José Llopis) dan en el blanco. En $S, B 1, O$ y $A$, puede leerse el siguiente pasaje a propósito del corazón, miembro rey, el pulmón, imán del viento, y la tráquea, musculoso claro arcaduz blando: 


\section{$\dashv$ Jorge Gutiérrez Reyna}

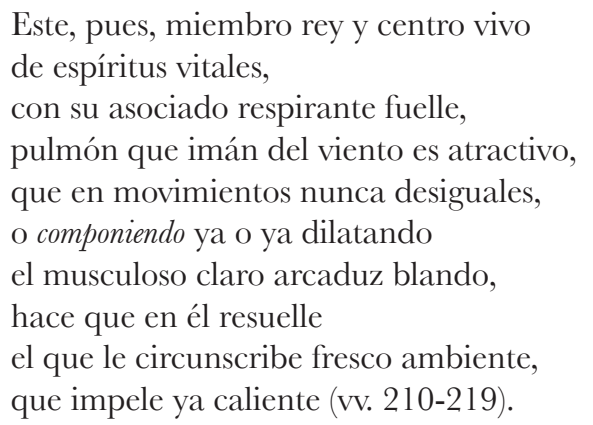

Todo apunta a que la lección del Segundo volumen es un error: el pulmón, como un fuelle, dilata y comprime, no "compone" la tráquea. Llopis, en una de las tres ediciones que en 1693 realizó en Barcelona del Segundo tomo de las obras de sor Juana (B2), propone una lección que hace pleno sentido y que han adoptado, sin titubear, todos los editores modernos: o comprimiendo ya o ya dilatando. El único comentarista contemporáneo del Sueño que se conoce, Pedro Álvarez de Lugo, tenía en sus manos esta edición de Llopis y, al hablar sobre el pasaje aludido, asume con toda naturalidad la variante comprimiendo: tanto para los lectores modernos como para uno de los tiempos de sor Juana, dicha lectura tiene sentido cabal (el comentario está editado por Sánchez, 1991). Considero que hay que aceptar, pues, la enmienda propuesta por Llopis para este verso, no sin antes advertir que sería uno de los dos únicos casos en que puede tomarse por bueno alguno de los cambios introducidos por el descuidado editor barcelonés al Primero sueño - el otro atañe al v. 824, pero de ello no me ocupo en este trabajo.

Hacia el final del poema, en unos versos bañados ya por la luz del amanecer, recuerda sor Juana al personaje mitológico de la Aurora. $S$ ofrece el siguiente texto:

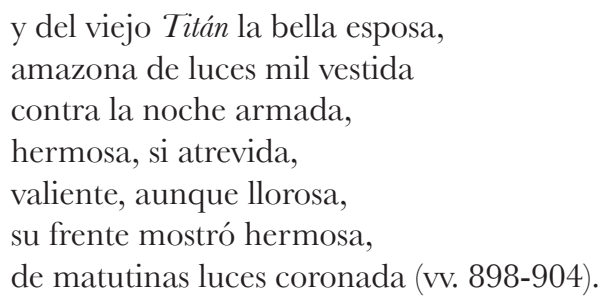

Karl Vossler sabía perfectamente que el nombre del esposo de la Aurora es Titón y, de manera consecuente, enmienda el verso: $y$ del viejo Titón la bella esposa. Creo que el cambio que propone Vossler y que los editores modernos - salvo Abreu Gómez y Alatorre - también aceptan es acertado. No hay duda de que sor Juana habla aquí de Titono o, como se decía, Titón, no de Titán, que es la lección que ofrecen, de forma 
invariable, las ediciones antiguas; así lo llama también Góngora en la segunda de sus Soledades, donde un "pescador anciano" expresa: "muchos ha dulces días/ que cisnes me recuerdan ['me despiertan'] a la hora/ que, huyendo la Aurora/ las canas de Titón, halla las mías" (vv. 392-395).

En algunas de las fuentes que la autora probablemente consultó, Titán es un personaje muy diferente al esposo de la Aurora, que es quien aparece en el Sueño. Tanto en las Metamorfosis de Ovidio traducidas por Bustamante (f. $5 \mathrm{r}$ y ss.) como en el Teatro de los dioses de la gentilidad de Baltasar de Victoria (6 y ss.), Titano o Titán es el hijo mayor - "robusto y muy feo", apunta Bustamante - de Urano y Gea, que cede a su hermano menor, Saturno, el reinado que le correspondía como primogénito. Titán es también, de acuerdo con estas fuentes, uno de los nombres que recibe el Sol, Apolo, por ser hijo del titán Hiperión. Del primer Titán, hermano de Saturno, habla sor Juana en el Neptuno alegórico; al describir el tercer lienzo, refiere que Asteria: "Fue hija de Ceo y nieta de Titán, aunque según otros, hija de éste y hermana de Latona" (1957: 401: líneas 819-820); ese fragmento es, por cierto, casi una cita de Baltasar de Victoria: "Asteria, hija de Ceo y nieta de Titán, aunque otros la hacen hija de Titán y hermana de la diosa Latona" (319). Sor Juana llamaba, pues, Titán a este hijo de Gea y Urano, y padre (o abuelo) de Asteria, por lo que no debía usar el mismo nombre para hablar del anciano esposo de la rosada Aurora.

Alatorre propone conservar la lección de Titán porque, según él, la confusión entre ambos nombres en los Siglos de Oro era frecuente y nuestra poeta bien pudo llamar Titán a Titón (1995: 406). Sin embargo, no encuentro pruebas que respalden lo anterior: lo normal es que los poetas áureos llamen Titón al esposo de la Aurora. Ahora bien, no parece infrecuente que en la imprenta, no en la mente de los poetas, Titón y Titán se confundan. Pongo sólo un ejemplo: en la princeps de la Arcadia de Lope de Vega se lee: "ya en los caducos brazos del viejo Titán descansaba con profundo sueño la colorada Aurora" (1598: f. 199v); pero al final del mismo volumen, en la "Exposición de los nombres poéticos y históricos contenidos en este libro", se informa: "Aurora, esposa de Titón, anunciadora del día" (s. f.). La primera de las menciones es una segura errata, porque Lope de Vega, en otras de sus obras, llama por su nombre al marido de la precursora del sol, como en su Isidro, publicado un año después de la Arcadia: "Ya de Titón, que la adora,/ dejando los brazos bellos,/ para verter perlas dellos/ sacaba la blanca Aurora/ los aurígeros cabellos" (1599: 185v). Si Lope distinguía entre Titón y Titán, no es de sorprender que sor Juana, la otra Fénix, pero de América, también lo hiciera: el Titón de las ediciones antiguas de su Sueño es una errata que exige ser enmendada. 


\section{Jorge Gutiérrez Reyna}

\section{Sor Juana imaginaria}

En el atardecer del siglo XVII, sor Juana conquistó al Viejo Mundo con el hechizo derramado de sus versos. Había de aquel lado del Atlántico un público ansioso de que desembarcara la obra que, en la soledad de su celda del Convento de San Jerónimo, concebía la monja mexicana. En uno de los poemas preliminares al Segundo volumen, que sor Juana leyó un día de octubre de 1692, don Pedro del Campo escribe esta simpática y reveladora cuarteta:

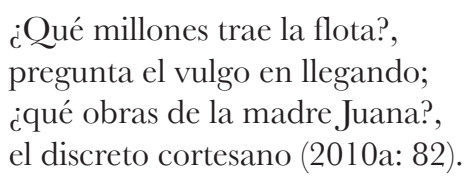

Apenas hemos empezado a comprender la dimensión de ese fenómeno editorial, a trazar la trayectoria transatlántica de los poemas de sor Juana, a conocer la historia de cada uno de esos editores que, en aquella época y en la nuestra, dieron a las prensas sus escritos, a veces con resultados primorosos, a veces no del todo. Para ofrecer a los lectores, tanto a los presentes como a los que vendrán, una versión digna no sólo de Primero sueño, sino de la obra en conjunto de nuestra poeta, es necesario que tracemos esos caminos, que contemos esas historias. De otro modo, estamos condenados a seguir leyendo a una sor Juana diversa de sí misma, no la que es, sino la que otros, sus editores, han querido imaginar.

\section{Bibliografía}

Ediciones de Primero sueño

\section{Antiguas}

S SEgundo VOlumen / DE las obras / DE SOROR / JVANa inés / DE LA CRVZ, / MONJA PROFESA EN EL MONASTERIO / DEL SEÑOR SAN GERÓNIMO / DE LA CIVDAD DE MÉXICO, / DEDICADO POR SV MISMA AUTORA / A D. JVAN DE ORUE / Y ARBieto / Cavallero de la orden de santiago. / Año <viñeta> 1692. / Con privilegio, En Sevilla, por tomás LóPEZ DE HARO, / Impreffor, y Mercader de Libros.

B1 SEGUNDO TOMO / DE LAS ObRAS / DE SOROR / JUANA INES / DE LA CRUZ, / MONJA PROFESSA EN EL MONASTERIO / DEL SEÑOR SAN GERONIMO / DE LA CIVDAD DE MEXICO. / AÑADIDO EN ESTA SEGVNDA IMPRESSION / POR SV AVTORA. / AÑO < viñeta> 1693. / < filete> / Impreflo en Barcelona, por Joseph Llopis. $Y$ à $\int u$ cofta.

88 (an)ecdótica vol. III, núm. 2, julio-diciembre 2019 
B2 SEGUNDO TOMO / DE LAS OBRAS / DE SOROR / JUANA INES / DE LA CRVZ / MONJA PROFESSA EN EL MONASTERio / DEL SEÑor SAN Geronimo / De la Ciudad de Mexico. / AÑAdido en ESTA SEGVNDA IMPRESSION / POR SV AVTORA. / Año < viñeta> 1693. / CON LAS LICENCIAS necessarias. / <filete> / Impreflo en Barcelona: Por Joseph Llopis. / Y à fu cofta.

B3 SEGUNDO TOMO / DE LAS ObRAS / DE SOROR / JUANA INÉS / DE LA CRUZ, / MONJA PROFESSA en el monasterio / del Señor san geronimo / De la Ciudad De Mexico. / añadido en ESTA SEGUNDA IMPRESSION / POR SU AUTORA. / Año < viñeta> 1693. / CON LAS LICENCIAS NeCESSARIAS. / < filete> / Impreflo en BARCELOna: por Joseph Llopis. / Y à su cofta.

O OBRAS POÉticas / DE LA MUSA MEXicana / SOROR / JUANA INÉS DE LA CRUZ, / RELIGIOSA Professa en el monasterio / del Gran Padre y Doctor de la Iglesia S. Gerónimo, / de la Ciudad de México. / tomo SEgundo, / AÑAdido POR SU Autora, / EN QUE VA EL CRISIS SOBRE Un SERMón / de vn Orador Grande entre los / mayores. / Año < viñeta> 1715. / Con licencia. / <filete> / En Madrid: En la IMPRENTA REAL, por Joseph Rodríguez de Efcobar, / Impreffor de la Santa Cruzada, y de la Real Academia Efpañola.

A SEGUNDO TOMO / DE LAS ObRAS / DE SOROR / JUANA INÉS / DE LA CRUZ, / MONJA PROFESSA EN EL / Monafterio del Señor San Geróni- / mo de la Ciudad de / México. / Pliegos <viñeta> 56 y m. / <filete> / Con Licencia: en Madrid. En la Imprenta de Ángel Paf- / qual Rubio. Año de 1725.

\section{Modernas}

AG Sor Juana Inés de la Cruz. "Primero Sueño". Edición de Ermilo Abreu Gómez. Contemporáneos, número 2 (julio 1928), 272-313.

KV Sor Juana Inés de la Cruz. "Primero Sueño", en Karl Vossler, Die Welt im Traum. Eine Dichtung der "Zaehnten Muse von México", Sor Juana Inés de la Cruz, Spanisch und Deutsch. Berlin: Herausgegeben, 1941, 73-107.

MP Sor Juana Inés de la Cruz. Obras completas. I. Lírica personal. Edición, prólogo y notas de Alfonso Méndez Plancarte. México: Instituto Mexiquense de Cultura/Fondo de Cultura Económica, 1951.

GM Sor Juana Inés de la Cruz. Primero sueño. Texto con introducción y notas. Buenos Aires: Imprenta de la Universidad, 1953 [edición a cargo de la Sección de Literatura Iberoamericana de la Universidad de Buenos Aires, con la colaboración de Juan Carlos Merlo y bajo el cuidado de Gerardo Moldenhauer].

SR Sor Juana Inés de la Cruz. Poesía, teatro, pensamiento: lírica personal, lírica coral, teatro, prosa. Edición, prólogo y notas de Georgina Sabat de Rivers y Elías Rivers. España: Espasa Calpe, 2004.

AA Sor Juana Inés de la Cruz. Obras completas. I. Lírica personal. Edición de Antonio Alatorre. México: Fondo de Cultura Económica, 2009. 


\section{Jorge Gutiérrez Reyna}

PA Alberto Pérez-Amador Adam. El precipicio de Faetón. Edición y comento de Primero Sueño de Sor Fuana Inés de la Cruz. Madrid/Frankfurt/México: Iberoamericana Vervuert/Universidad Autónoma Metropolitana-Iztapalapa, 2015.

\section{Referencias bibliográficas}

Alatorre, Antonio

"Notas al Primero sueño de sor Juana", en Nueva Revista de Filología Hispánica, volumen 43, número 2 (1995), 309-407.

Sor Juana a través de los siglos (1668-1910). Tomo 2. México: El Colegio de México/Universidad Nacional Autónoma de México, 2007.

"Hacia una edición crítica de sor Juana (apéndice)", en Nueva Revista de Filología Hispánica. México: El Colegio de México, Centro de Estudios Lingüísticos y Literarios, volumen LVII, número 2 (2009), 777-782.

Blecua, Alberto

Manual de crítica textual. Madrid: Castalia, 2018.

BRYANT, William C.

"Reaparición de una poesía de Sor Juana Inés de la Cruz, perdida desde 1714", en Anuario de Letras. México: Universidad Nacional Autónoma de México, Facultad de Filosofía y Letras, Centro de Lingüística Hispánica, volumen IV (1964), 277-285.

Calvo, Hortensia y Beatriz Colombi

Cartas de Lysi. La mecenas de sor Juana Inés de la Cruz en correspondencia inédita. Madrid/Frankfurt/México: Iberoamericana/Vervuert/Bonilla Artigas, 2015.

Cerone, Pedro

El melopeo y el maestro. Tratado de música teórica y práctica. Libro primero. Nápoles: Juan Bautista Gargano y Lucrecio Nucci, 1613.

Corripio Rivera, Manuel

"Una minucia en El sueño de sor Juana: ¿Almone o Alcione?", en Ábside. Revista de Cultura Mexicana. México, volumen XXIX (1965), 472-481.

Gruz, sor Juana Inés de la

Obras completas. I. Lírica personal. Edición, prólogo y notas de Alfonso Méndez Plancarte. México: Fondo de Cultura Económica, 1951.

Obras completas. IV. Comedias, sainetes y prosa. Edición, introducción y notas de Alberto G. Salceda. México: Fondo de Cultura Económica, 1957.

90 (an)ecdótica vol. III, núm. 2, julio-diciembre 2019 


\section{El texto del Primero sueño}

Obras completas. I. Lírica personal. Edición de Antonio Alatorre. México: Fondo de Cultura Económica, 2009.

Segundo volumen de sus obras. Edición facsimilar. Introducción de Margo Glantz. México: Universidad Nacional Autónoma de México, Facultad de Filosofía y Letras, 2010a.

Fama y obras póstumas. Edición facsimilar. Introducción de Antonio Alatorre. México: Universidad Nacional Autónoma de México, Facultad de Filosofía y Letras, 2010b.

\section{Eguía Lis Ponce, Luz Gabriela}

"'La prisa de los traslados'. Análisis crítico e interpretación de variantes encontradas en las ediciones antiguas (siglos XVII y XVIII) de los tres tomos de la obra de sor Juana Inés de la Cruz”. Tesis de doctorado. México: Universidad Nacional Autónoma de México, 2002.

\section{Galicia Lechuga, David y Jorge Gutiérrez Reyna}

"Un impresor seducido por sor Juana: los textos de las sueltas novohispanas publicados por José Llopis en Poemas (1691)", en Caliope. Pensilvannia: Penn State University, Society for Renaissance and Baroque Hispanic Poetry, volumen XXIII, número 2 (2018), 217-233.

\section{GLANTZ, Margo}

"Introducción", en Sor Juana Inés de la Cruz. Segundo volumen de sus obras. Edición facsimilar. México: Universidad Nacional Autónoma de México, Facultad de Filosofía y Letras, 2010, XI-LXIX.

GóNGORA, Luis de

Soledades. Edición de Robert Jammes. Madrid: Castalia, 2001.

\section{GutiérRez Reyna, Jorge}

"Los villancicos de sor Juana Inés de la Cruz. Edición crítica, prólogo y notas". Tesis de maestría. México: Universidad Nacional Autónoma de México, 2016.

\section{OVIDIO}

Las transformaciones. Traducción, comento y explicación de Pedro Sánchez de Viana. Valladolid: Diego Fernández de Córdoba, 1589.

Las metamorfoses o transformaciones. Traducción de Jorge de Bustamante. Madrid: Domingo Morrás, 1664.

Metamorfosis. Libros I-IV. Introducción, versión rítmica y notas de Rubén Bonifaz Nuño. México: Universidad Nacional Autónoma de México, 1979.

PAz, Octavio

Sor Fuana Inés de la Cruz o las trampas de la fe. México: Fondo de Cultura Económica, 1984.

Rodríguez Cepeda, Enrique

"Las impresiones antiguas de las Obras de sor Juana en España (un fenómeno olvidado)", 


\section{$\downarrow$ Jorge Gutiérrez Reyna}

en José Pascual Buxó (editor). Sor Fuana Inés de la Cruz y las vicisitudes de la crítica. México: Universidad Nacional Autónoma de México, Instituto de Investigaciones Bibliográficas, Seminario de Cultura Literaria Novohispana, 1998, 13-75.

Sabat de Rivers, Georgina

"Nota bibliográfica sobre sor Juana Inés de la Cruz. Son tres las ediciones de Barcelona, 1693", en Nueva Revista de Filología Hispánica. México: El Colegio de México, Centro de Estudios Lingǘsticos y Literarios, volumen XXIII, número 2 (1974), 391-401.

Bibliografia y otras cuestiúnculas sorjuaninas. Salta: Biblioteca de Textos Universitarios, 1995.

Sánchez Robayna, Andrés

Para leer "Primero sueño" de sor Fuana Inés de la Cruz. México: Fondo de Cultura Económica, 1991.

Terreros y Pando, Esteban

Diccionario castellano: con las voces de ciencias y artes y sus correspondientes en las tres lenguas francesa latina e italiana. Madrid: Viuda de Ibarra, 1787.

Vega, Lope de

Arcadia, prosas y versos. Con una exposición de nombres históricos y poéticos. Madrid: Luis Sánchez, 1598.

Isidro. Poema castellano. Madrid: Luis Sánchez, 1599.

Victoria, Baltasar de

Teatro de los dioses de la gentilidad. Salamanca: Antonio Ramírez, 1620. 